\title{
Checking the conformity of the grain-size composition of road cement concrete mixtures
}

\author{
Artur Onyshchenko, ${ }^{1,}$, Sergii Aksonov ${ }^{1}$, Vitalii Stozhka ${ }^{1}$, Mykola Garkusha ${ }^{1}$, and Alexandr \\ Matusevich $^{2}$ \\ ${ }^{1}$ National Transport University 1, M. Omelianovych-Pavlenko Str. Kyiv, Ukraine 01010 \\ ${ }^{2}$ Moscow State University of Civil Engineering, Yaroslavskoe shosse, 26, Moscow, 129337, Russia
}

\begin{abstract}
The article is devoted to operational quality control of grainsize composition of cement-concrete road mixtures for use on highways of Ukraine. The results of the experimental research are presented, which testify to the non-conformity of the planned grain composition to the actual production composition, as well as the influence on it of a number of factors that significantly affect the quality of the mixture and the durability of cement concrete.
\end{abstract}

\section{Introduction}

Road cement concrete used in aggressive environments can be destroyed if the designer or the builder did not take into account the results of the joint action of traffic intensity and axle load increase of road transport, physical and chemical factors. One of the reasons for the destruction of road cement concrete is the poor quality of aggregates, the wrong choice of grain-size analysis, especially the fine aggregate, as well as the ratio between fine and coarse aggregates, which leads to a high void ratio of the mineral aggregate of cement mortar and concrete. This increases the amount of free and physically-bounded moisture in concrete and leads to increased mass-volume processes and evaporation of water. The resulting looseness of the upper layer and a significant capillary porosity not only facilitate the penetration of aggressive media into the depth of concrete but also result in a significant deterioration of the concrete surfacing, which reduces the length of its service life. We can also add to these reasons the wrong choice of chemical additives and unreasonably increased cement costs. Irrational choice of chemicals and air-entraining admixtures used can lead to an increase in the amount of free moisture that does not participate in the formation of the structure. At the same time, the structure of concrete is destroyed and its operational properties are reduced. Therefore, the purpose of the paper is to develop a method of grain-size analysis of cement-concrete road mixtures while exercising the operational control over their quality.

\section{Literature analysis}

\footnotetext{
*Corresponding author: artur_onish@bigmir.net
} 
As it is known, the current regulatory documents of Ukraine [1 - 3] on cement-concrete technologies allow calculating the composition of a cement-concrete mixture, but do not allow controlling the conformity of the actual grain-size composition of cement-concrete road mixtures.

There is also a European experience in designing the composition of a mixture of aggregates for heavy concrete, which is given in standards [4, 5] and [6]. Since the sieve curves describe the standard distribution of particles of 0.125 to $40.0 \mathrm{~mm}$ fractions, these standards, based on the standard curves of distribution of particles by sieve size, indicate in which boundaries the ratio of the aggregate fractions can be changed to make the concrete structure close to the optimal structure in terms of strength and recommend using a cubeshaped multi-grade aggregate.

The results of the experimental research testify to the non-conformity of the planned grain composition to the actual production composition, as well as the influence of a number of factors on it that significantly affect the quality of the mixture.

The literature analysis makes it clear that the properly selected grain-size composition reduces the need for water in order to obtain the most easily cast cement-concrete mixture, thus obtaining the required density and structure of cement concrete that provide the corresponding quality. Thus, the optimization of the grain composition results from the basic requirement: to get the smallest amount of intergranular air voids in the aggregate and thus ensure the necessary expense of cement in cement concrete.

The increase in the durability of road concrete can be achieved by increasing the strength and density of concrete by improving the methods of selecting the composition [1, 2, 7-11, 12] and the use of modern chemical and mineral additives, which reduce the water consumption of a concrete mix. Thus, the thickness of the water film on the particles of aggregates is reduced, i.e. free and physically-bounded moisture is reduced. At the same time, the main strength indicator is the amount of an aggregate of cement-concrete mixture per unit volume and its conformity to the planned grain-size composition.

Therefore, the results of the analysis indicate the need to determine the grain-size composition of cement-concrete road mixtures while exercising the operational control over their quality, which will ensure the durability of cement-concrete road surfacing.

\section{Main part}

The development of the technique consists in the operational quality control over the grain-size composition of cement-concrete road mixtures for use on the highways of Ukraine.

The verification of the conformity is a combination of decisions and actions performed in accordance with pre-adopted rules for determining the conformity of a cement-concrete mixture and cement concrete to specified requirements in accordance with [7] and [8].

The conformity assessment is carried out in relation to the specified characteristics of the cement-concrete mixture and cement concrete. Tests are performed according to standard methods according to [7-8]. Actual values of the properties of cement concrete in the construction may differ from the results of sample tests, for example, depending on the size of structures, cast, consolidation, curing, construction operating conditions, but must conform to the design requirements [9-10].

The technical requirements for cement concrete must be provided by its manufacturer at the design age, which is indicated in the design documentation in accordance with [14] and [15].

The components of the cement-concrete mixture must not contain any hazardous substances that could affect the life of the cement concrete or cause corrosion of the reinforcement. 
Requirements for road cement concrete aggregates

Coarse aggregate. In order to prepare cement-concrete mixtures, it is necessary to use as coarse aggregate crushed stone made of natural stone, gravel, crushed gravel, slag crushed stone, as well as crushed rock from the surrounding rocks and from solids of dry magnetic dressing of ferruginous quartzite, according to [13-14].

The largest aggregate coarseness for single-layer surfacing of highways must be $40 \mathrm{~mm}$, and for the top layer of two-layer surfacing - $20 \mathrm{~mm}$.

Fine aggregate. To prepare cement-concrete mixtures for road surface layers, one must use as a fine aggregate natural sand, gravel sand from crushing of igneous rocks according to [15], which meet the requirements [16] for grain composition, slime and clay particles content, fineness modulus, and water absorption indicator.

From the many years of practice in foreign and Ukrainian materials science, the modulus of elasticity of concrete for road construction must be $37-42 \cdot 103 \mathrm{MPa}$ (with 5 $6 \%$ of entrained air content). Instead, the modulus of elasticity of granite macadam is $70-$ $90 \cdot 103 \mathrm{MPa}$, and of the mortar $-15-26 \cdot 103 \mathrm{MPa}$. On this basis, it is necessary to limit the amount of coarse aggregate: $1050-1250 \mathrm{~kg}$ for $\mathrm{r}=0.35-0.43$ and $950-1100 \mathrm{~kg}$ for $\mathrm{r}$ $=0.43-0.48$. The ratio between fine and coarse aggregates $(\mathrm{r})$. With fine sand, Mco $\leq 1.8 \mathrm{r}$ $=0.35-0.4$, with medium coarse sand, $\mathrm{Mco}=1.8-2.1 \mathrm{r}=0.38-0.43$, with coarse sand, $\mathrm{Mco} \geq 2.2 \mathrm{r}=0.43-0.48$.

According to the method of calculating the composition of concrete, the amount of a coarse aggregate used is determined based on the condition of formation of a continuous rigid frame with optimal volumetric placement of grains of a coarse aggregate, resulting in the increase in strength of cement concrete under equal conditions by $15-20 \%$.

At present, two methods of selecting a cement concrete composition have become widespread. According to the standard method [1,2], the amount of coarse aggregate (crushed stone) is determined by the formula:

The amount of coarse aggregate (crushed stone) is determined by the formula:

$$
C s=\frac{1000}{\frac{c_{e} \cdot V n^{c s}}{\gamma_{0}^{c s}}+\frac{1}{\gamma^{c s}}},
$$

where: ce is the coefficient of expansion;

$\gamma_{0}^{c s}$ is the bulk density of crushed stone, $\mathrm{kg} / \mathrm{m} 3$;

$\gamma^{c s}$ is the absolute density of crushed stone, $\mathrm{kg} / \mathrm{m} 3$.

The volume of the mortar phase is determined by the formula:

$$
V_{m}=k_{c s} \cdot V_{v}^{c s}+\left(1-k_{c s}-V_{a}\right)
$$

where: $V_{a}$ is the air content in cement concrete;

$V_{v}^{c s}$ is the void ratio of crushed stone in a compacted state.

$$
V_{v}^{c s}=\frac{\gamma^{c s}-\gamma_{0}^{c s}}{\gamma^{c s}}
$$

When $V_{a}=0, V_{\sigma}=1000 l$, then formula (4) looks as follows:

$$
V_{m}=k_{c s} \cdot V_{v}^{c s}+\left(1-k_{c s}\right) \text {. }
$$

The content of fine aggregate (sand) is determined by the formula: 


$$
S=\left(V_{m}-\frac{C}{\gamma^{c}}-\frac{B-B_{c s}}{1000}\right) \cdot \gamma^{s},
$$

Determination of the ratio between fine $(S)$ and coarse $(C S)$ aggregate (sand and crushed stone, respectively):

$$
r=\frac{S}{C S+S}
$$

The main factor of the rheological properties of a cement-concrete mixture is the coefficient of expansion of crushed stone grains. Using the coefficient of expansion of crushed stone grains $\left(c_{e}\right)$ is pre-determined by the amount of static-void coarse aggregate $(C S)$ (crushed stone) and the volume of the binding agent (cement rock).

The optimality of the structure of selection of cement-concrete mixture composition should be determined not only by the minimum porosity of the mixture of fine and coarse aggregates (sand and crushed stone) and the amount of the binding agent but also by the necessary technological properties and economic expediency.

With the conditions of obtaining the material, the maximum bending tensile strength must be determined depending on the density of crushed stone in a shaking condition, which depends on the content of acicular and plated fractions.

The densest packing also depends on the fineness modulus of the sand and its density in a shaking condition, taking into account the fraction of $0.315 \ldots 0.63$. After establishing the optimal ratio of $C S: S$ in the control structure, the consumption of additives is selected taking into account the air (gas) entraining component. This gives a rational pore structure (the distribution of the entrained air (gas) mainly in the volume of the mortar phase. This reduces defects in cement rock (the minimum content of air around a coarse aggregate).

All this increases the homogeneity and, consequently, frost resistance of the concrete, and together with the increase of bending tensile strength and the decrease of the modulus of elasticity, it increases the durability of cement concrete.

Proper selection of the composition (packing) of the concrete mixture, as well as the structure and viscosity of the chemical additive, make it possible to distribute the air (gas) bubbles in the mortar phase of the concrete mixture and the cast cement concrete and minimizes the distribution of air bubbles near the coarse aggregate, i.e. the structure of the defects is reduced. Reducing the structure of defects leads to an increase in bending tensile strength, frost resistance, and watertightness, and the reduction in capillary porosity by $\leq$ $1.5 \%$. This makes it possible to reduce the amount of air when using air-entraining additives to $4.0-4.5 \%$ or gas-forming additives to $2.8-3.5 \%$ at the frost resistance of F300 [17].

\section{Grain-size analysis of cement-concrete road mixtures}

The suggested method of grain-size analysis of cement-concrete road mixtures consists of the following operations [18, 29]:

- Determination of the amount of a coarse aggregate.

- Determination of the amount of a fine aggregate (sand).

The method involves the separation from the cement-concrete mixture of a coarse aggregate and a fine aggregate, and the decomposition (in fractions) in the specified sequence (sieve method).

The grain-size analysis of cement-concrete road mixtures allows providing the relative accuracy up to $10 \%$. 


\subsection{Sampling for analysis}

Samples of cement-concrete mixtures for testing under the operational control should be taken:

-At the place of preparation of a cement-concrete mixture when loading into a transport capacity.

- At the place of casting the cement-concrete mixture.

The sample of a cement-concrete mixture must most accurately reflect the composition of cement concrete in this part of the construction. To do this, two samples are taken from three different points per pour.

Depending on the maximum size of cement concrete aggregates, the dimensions of the structural element, and other factors, the mass of each point sample may vary from 5 to 10 $\mathrm{kg}$.

From the point samples, an integrated test sample is formed, which characterizes the controlled batch.

The mass of the integrated test sample for the operational control of the cementconcrete mixture must not be less than the one specified in Table 1 .

In sampling, it is possible to use the mixture after controlling the consistency of the concrete mixture in accordance with [19].

Testing of the cement-concrete mixture must begin not later than two hours after sampling.

Table 1. The mass of the integrated test sample of the material depending on the largest size of the aggregate grains

\begin{tabular}{|c|c|}
\hline $\begin{array}{c}\text { The largest grain size D, } \\
\text { mm }\end{array}$ & Sample weight, kg \\
\hline 10 & 5.0 \\
\hline 20 & 10.0 \\
\hline 40 & 20.0 \\
\hline 80 & 40.0 \\
\hline
\end{tabular}

\subsection{Testing. Means of control and auxiliary equipment}

A set of sieves with openings of the desired size according to [20]. Laboratory scales of Accuracy Rating 4 according to [21], providing a weighing error of $\pm 0.1 \mathrm{~g}$.

A drying box, which provides heating to a temperature of $105 \pm 5^{\circ} \mathrm{C}$ and maintains the set temperature for the required time with an error of $\pm 5^{\circ} \mathrm{C}$. A cup of porcelain from 15 to $25 \mathrm{~cm}$ in diameter in accordance with [22].

A pounder with a rubber tip.

A container with a capacity of 6 to 10 liters.

Water according to [23].

\subsection{Testing and processing of results}

From the integrated test sample of a cement-concrete mixture, two test samples are selected, each in a volume of:

$1 \mathrm{dm}^{3}$ - for a cement-concrete mixture with the largest grain size of up to $20 \mathrm{~mm}$.

$3 \mathrm{dm}^{3}$ - for a cement-concrete mixture with the largest grain size of up to $80 \mathrm{~mm}$.

The cement-concrete mixture is weighed in a measuring metal cylinder, then poured into a porcelain cup (a metal bowl may be used as well), overwatered with a small amount 
of water ( $8-10 \%$ from the mass of the mixture), and pestled with the rubber-tip pounder for two to three minutes.

The aggregates are separated from the cement binding agent by washing the cementconcrete mixture with water.

Water with particles stuck in is drained through a sieve with mesh no. 0071, placed over the container with a capacity of 6 to 10 liters. The particles left in the cup are overwatered again with clear water, pestled, and water is drained again.

Washing out and pestling of mineral material directly on the sieve with mesh no. 0071 are not allowed.

The successive pestling of particles and draining of muddy water continue until the water is transparent. When the washing out is finished, the particles of mineral material of more than $0.071 \mathrm{~mm}$ in size, remaining on the sieve, are transferred to the porcelain cup. The remaining water in the cup is carefully drained, after which the cup is placed in a drying box to dry the mineral material (coarse and fine aggregates) to a stationary mass at a temperature of $105 \pm 5{ }^{\circ} \mathrm{C}$. The mass is considered to be stationary when the difference between two successive weighing operations with an interval of 1 hour does not exceed $0.1 \%$ of the mass of the weight gain.

During the testing, express drying of the aggregates may be applied. After the water is drained from the cup, the cup is placed in the drying box to dry the mineral material (coarse and fine aggregates) to a stationary mass at a temperature of $145 \pm 5{ }^{\circ} \mathrm{C}$. The mass is considered to be stationary when the difference between two successive weighing operations with an interval of 1 hour does not exceed $0.1 \%$ of the mass of the weight gain $[3,24]$.

After drying, the composition of the aggregates is determined to check for conformity with the planned composition, taking into account allowable deviations according to [25], [28].

Dried mineral samples are combined and sieved manually or mechanically through a set of sieves according to [25-26].

Based on the results of sieving, the partial remainder on each sieve $a_{i}$ is determined by the formula:

$$
a_{i}=\frac{m_{i}}{m} 100
$$

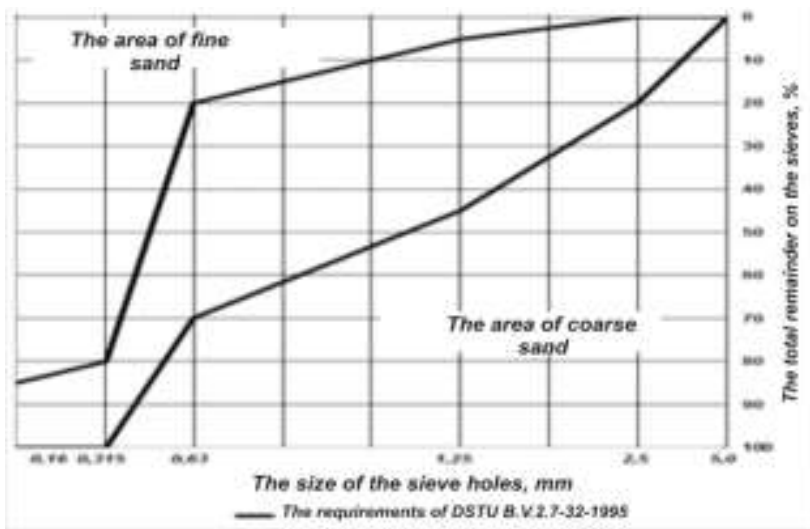

Fig.1. The grain composition of the sand

where $\mathrm{m}_{\mathrm{i}}$ is the mass of the remainder on this sieve, $\mathrm{g}$; $\mathrm{m}$ is the sample mass, $\mathrm{g}$. 
The total remainder on each sieve is determined as a percentage of the sample mass, equal to the sum of partial remainders on the given sieve and all the sieves with large-sized holes.

Before finishing the sieving, each sieve is shaken vigorously for checking purposes for $60 \pm 5 \mathrm{~s}$ above a sheet of paper. Sieving is considered to be completed under the following conditions:

- If there are no particles on the paper that have passed through the sieve with holes of 2.5 $\mathrm{mm}$ or more in size.

- If the mass of particles that have passed through the sieve with holes of $1.25 \mathrm{~mm}$ and 0.63 $\mathrm{mm}$ in size does not exceed $0.05 \mathrm{~g}$, and the mass of particles that have passed through the sieve with holes of $0.071 \mathrm{~mm}$ in size does not exceed $0.02 \mathrm{~g}$.

The particles that have passed through the sieve are added to the particles that have passed through the sieves with smaller holes. The remainder on each sieve is weighed, and the partial remainders on the sieves are determined as a percentage of the mass of the sieved weight gain, rounded to the first decimal mark.

The content of grains smaller than $0.071 \mathrm{~mm}$ in percent is defined as the difference between $100 \%$ and the total remainder on the sieve of $0.071 \mathrm{~mm}$ in size.

The arithmetic mean of two parallel tests is taken as the result of the test.

The difference between the results of parallel tests on a single sieve must not exceed $2 \%$ of the total mass of the weight gain. The mass fraction of material losses during sieving must not exceed $2 \%$ of the weight gain taken.

The sampling point for making samples should be chosen in such a way as to exclude the effect of the sampling point and delivery conditions on the composition and properties of the cement-concrete mixture [1].

The grain composition of sand is determined according to [27], which must meet the requirements of [2], [16] and Figure 1.

The content of grains with the size of 5.0 to $10.0 \mathrm{~mm}$ in all types of sand can be up to $5 \%$ by weight, and grains with the size of more than $10 \mathrm{~mm}$ - to $0.5 \%$ by weight.

The grain composition of crushed stone and crushed gravel is characterized by:

- The largest (D) and the least (d) nominal grain size of fractions or mixtures of fractions, $\mathrm{mm}$.

- The value of total remainders on the test sieves.

The content of individual fractions in a coarse aggregate in a cement concrete composition must be as specified in Table 2, according to [6], [2].

Table 2. The content of fractions in a coarse aggregate

\begin{tabular}{|c|c|c|c|c|}
\hline \multirow{2}{*}{$\begin{array}{l}\text { The largest } \\
\text { aggregate } \\
\text { coarseness, } \\
\text { mm }\end{array}$} & \multicolumn{4}{|c|}{$\begin{array}{c}\text { The content of fractions in a coarse aggregate, } \\
\%\end{array}$} \\
\hline & $\begin{array}{l}\text { From } 5 \text { to } \\
10 \mathrm{~mm}\end{array}$ & $\begin{array}{l}\text { Over } 10 \\
\mathrm{~mm} \text { to } 20 \\
\mathrm{~mm}\end{array}$ & $\begin{array}{l}\text { Over } 20 \\
\mathrm{~mm} \text { to } 40 \\
\mathrm{~mm}\end{array}$ & $\begin{array}{l}\text { Over } 40 \\
\mathrm{~mm} \text { to } 80 \\
\mathrm{~mm}\end{array}$ \\
\hline 10 & 100 & - & - & - \\
\hline 20 & $25-40$ & $60-76$ & - & - \\
\hline 40 & $12-25$ & $20-35$ & $40-65$ & - \\
\hline $70(80)$ & $10-20$ & $15-25$ & $20-35$ & $35-55$ \\
\hline
\end{tabular}

The value of the total remainders on the test sieves must meet the requirements of [28] and Figure 2.

In the crushed stone of fractions from 5 to $10 \mathrm{~mm}$, from 10 to $20 \mathrm{~mm}$, from 20 to 40 $\mathrm{mm}$ and a mixture of fractions from 5 to $20 \mathrm{~mm}$, from 5 to $40 \mathrm{~mm}$, from 10 to $40 \mathrm{~mm}$, and from 20 to $70(80) \mathrm{mm}$, up to $20 \%$ of grains of more than D and less than $\mathrm{d}$ in size by 
weight of crushed stone are allowed in the content. The content of grains of less than $0.5 \mathrm{~d}$ in size in crushed stone must not be more than $10 \%$ by weight in accordance with [28].

The crushed stone supplied in the form of a mixture of fractions with the grain size from 5 to $20 \mathrm{~mm}$, from 5 (10) to $40 \mathrm{~mm}$, must have a value of total remainders on the test sieves of $0.5(d+D)$ from $30 \%$ to $80 \%$; for a mixture of fractions of a grain size from 20 to 70 $(80) \mathrm{mm}$, the value of total remainders on test sieves of $0.5(\mathrm{~d}+\mathrm{D})$ must be from $30 \%$ to $70 \%$.

Crushed stone and gravel must not have grains of the following size:

- Over $1.25 \mathrm{D}$ - in fractions and mixtures of fractions from 40 to $70(80) \mathrm{mm}$.

- Over $1.5 \mathrm{D}$ - in fractions and mixtures of fractions from 20 to $70(80) \mathrm{mm}$, from 20 to $40 \mathrm{~mm}$, and from 5 (10) to $40 \mathrm{~mm}$.

- Over 2D - in fractions from 10 to $20 \mathrm{~mm}$, from 5 to $20 \mathrm{~mm}$, and from 5 to $10 \mathrm{~mm}$.

The maximum grain size of sandy mixtures must not exceed $10 \mathrm{~mm}$ (2D).

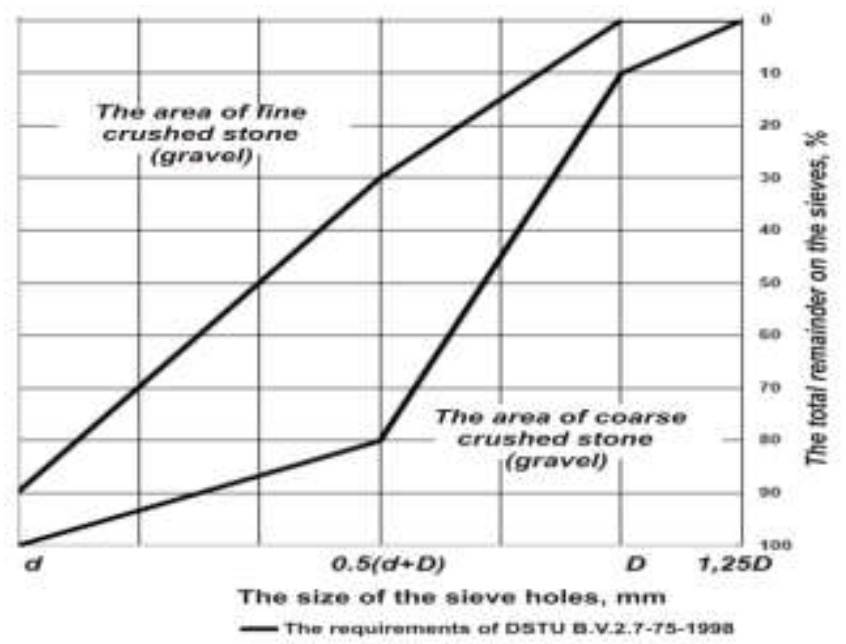

Fig. 2. Crushed stone (gravel) grain composition

In case of non-conformity of grain composition of [25] and [28], cement-concrete road mixtures are not allowed for use.

\section{Experimental research}

Laboratory and full-scale studies on checking the grain composition of cement-concrete mixture aggregates were carried out at the leading enterprises of the construction industry of Ukraine. The stages of the experimental research are depicted in Fig. $3-6$. The stages of the experimental research are depicted in Fig. $3-6$. 


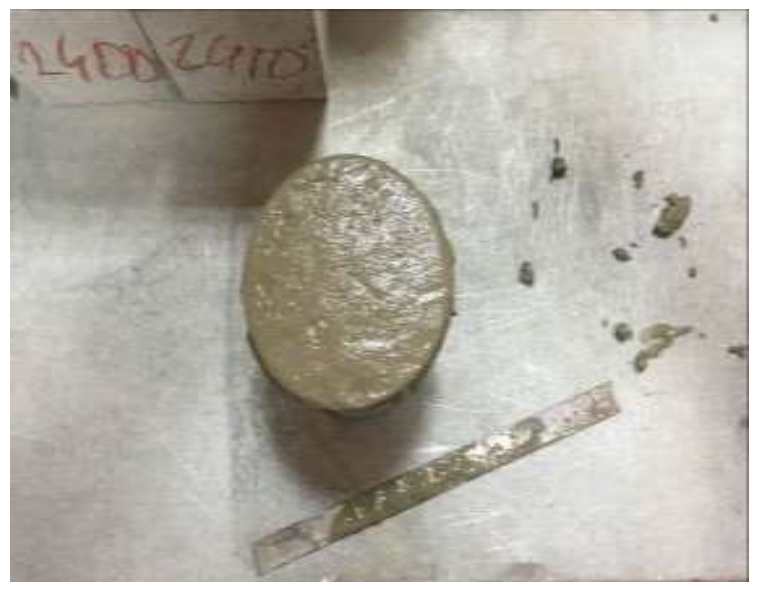

Fig. 3. Sampling

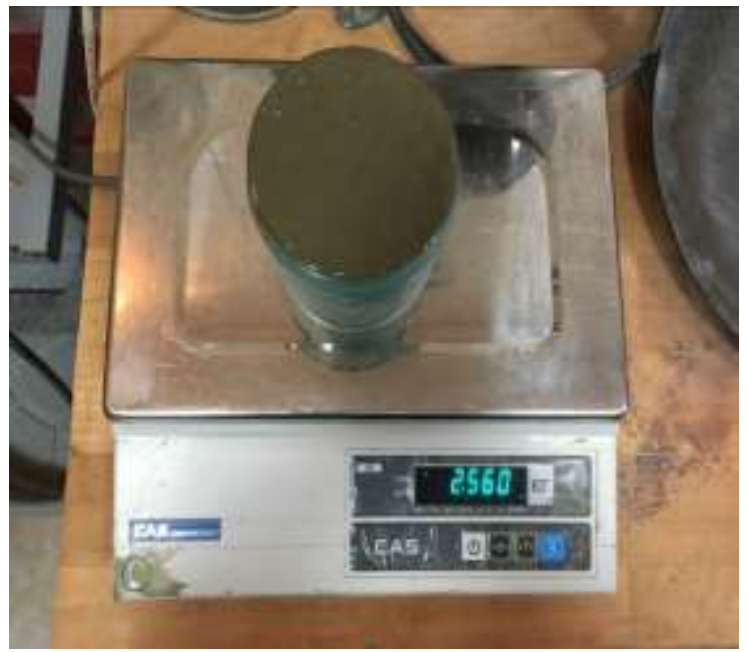

Fig. 4. The weighing of the selected sample to determine its density

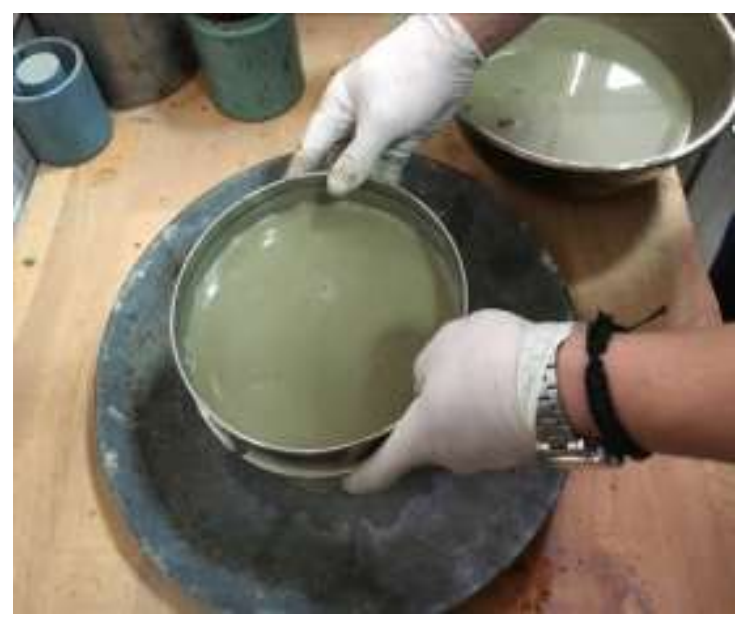

Fig. 5. Washing out the cement-concrete mixture 


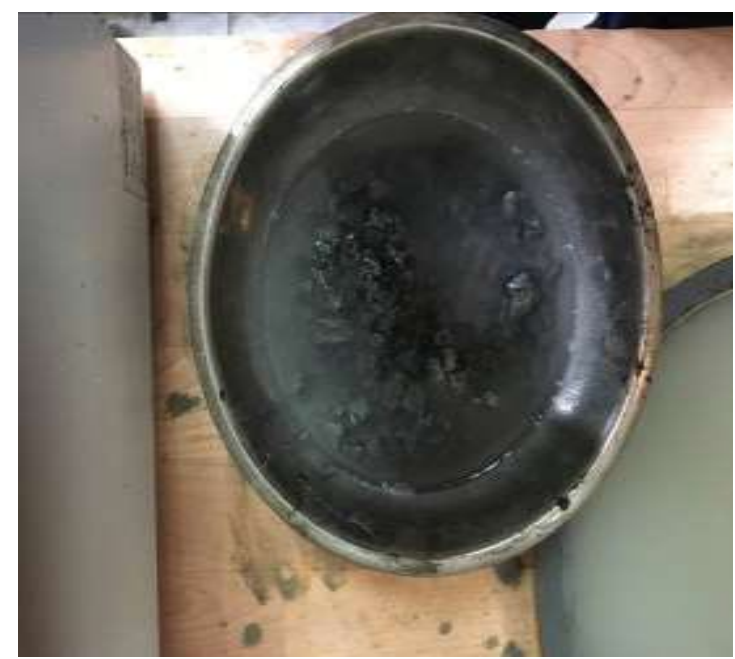

Fig. 6. The appearance of the mixture after washing out

The test results are shown in Figures $7-15$.

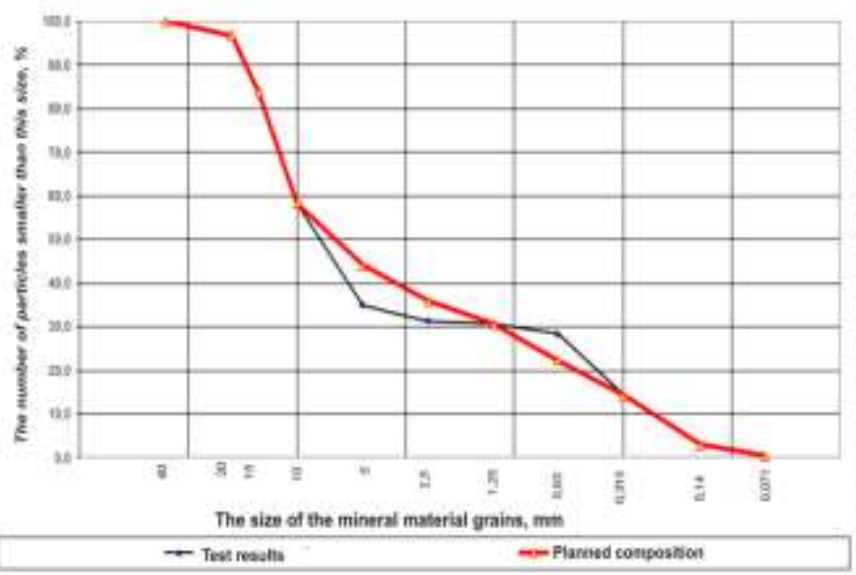

Fig. 7. The test results of the mixture at a temperature of $+5^{\circ} \mathrm{C}$ (immediately after the preparation) B30 P3 F200 W2 


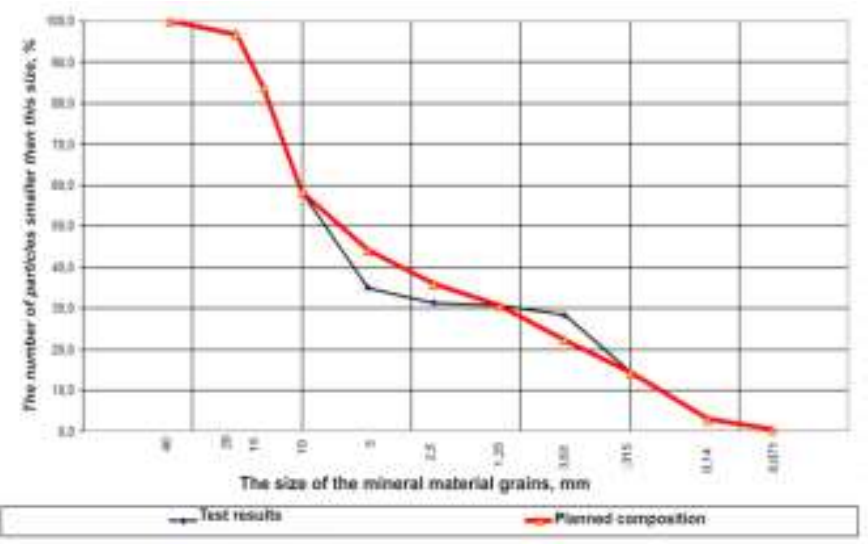

Fig. 8. The test results of the mixture at a temperature of $+5^{\circ} \mathrm{C}$ ( 45 minutes after the preparation) $\mathrm{B} 30$ P3 F200 W2

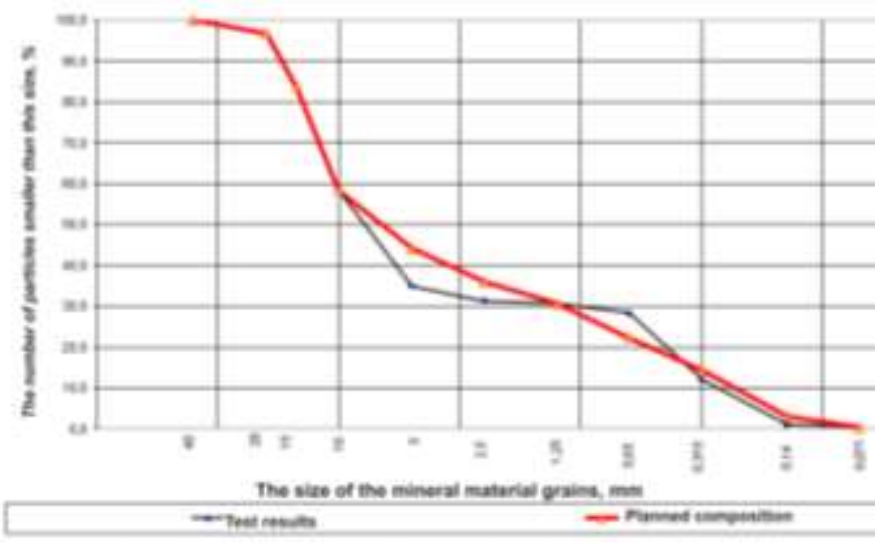

Fig. 9. The test results of the mixture at a temperature of $+5^{\circ} \mathrm{C}$ ( 2 hours after the preparation) $\mathrm{B} 30 \mathrm{P} 3$ F200 W2

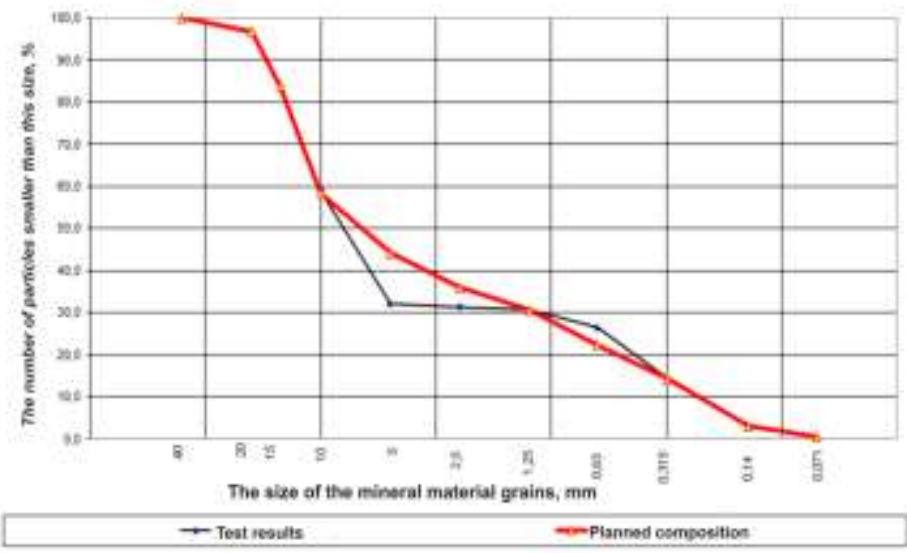

Fig. 10. The test results of the mixture at a temperature of $+20^{\circ} \mathrm{C}$ (immediately after the preparation) B30 P3 F200 W2 


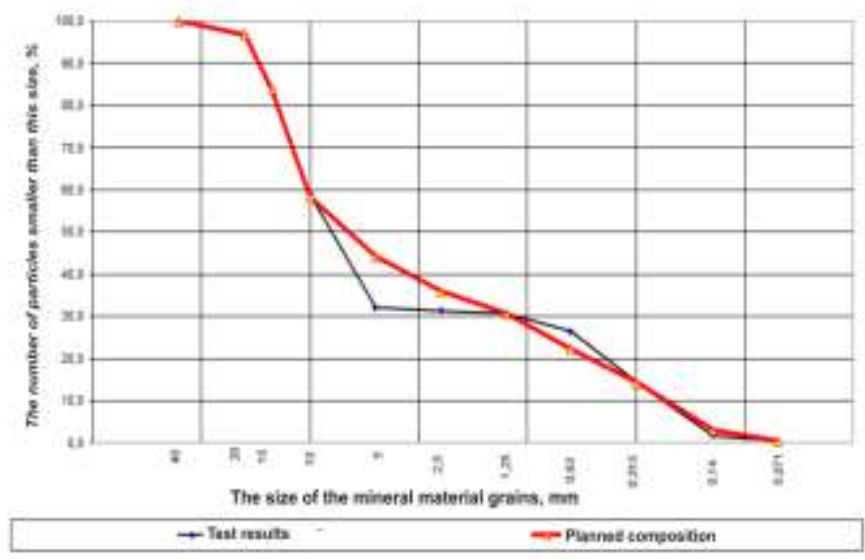

Fig. 11. The test results of the mixture at a temperature of $+20^{\circ} \mathrm{C}$ ( 45 minutes after the preparation) B30 P3 F200 W2

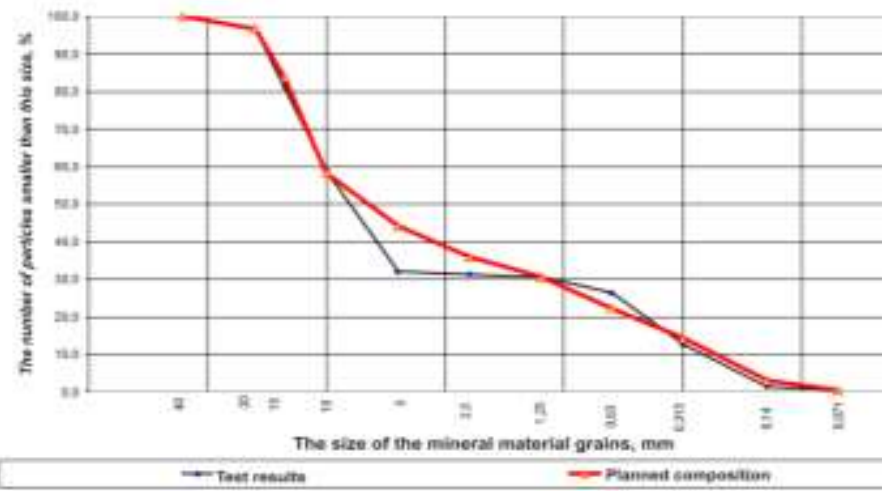

Fig. 12. The test results of the mixture at a temperature of $+20^{\circ} \mathrm{C}$ ( 2 hours after the preparation) $\mathrm{B} 30$ P3 F200 W2

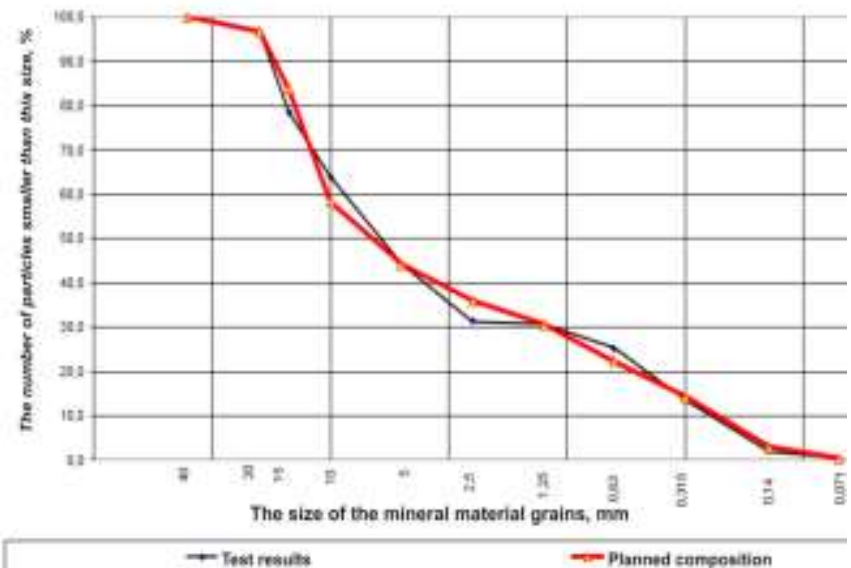

Fig. 13. The test results of the mixture at a temperature of $+35^{\circ} \mathrm{C}$ (immediately after the preparation) B30 P3 F200 W2 


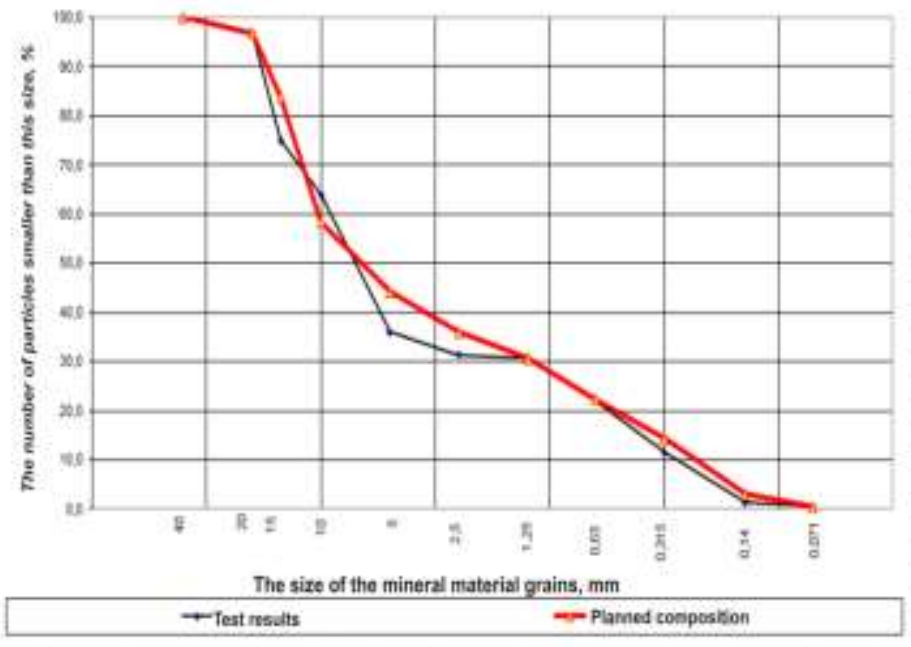

Fig. 14. The test results of the mixture at a temperature of $+35^{\circ} \mathrm{C}$ ( 45 minutes after the preparation) B30 P3 F200 W2

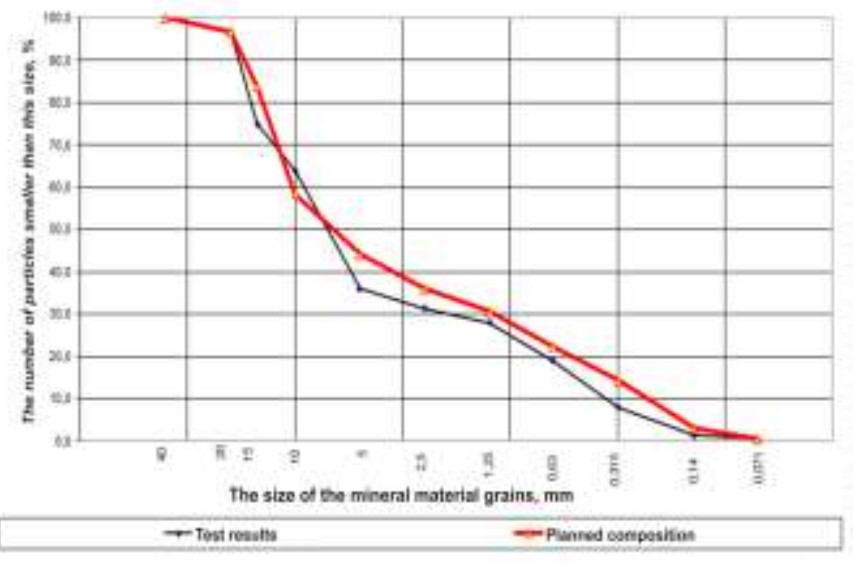

Fig. 15. The test results of the mixture at a temperature of $+35^{\circ} \mathrm{C}$ ( 2 hours after the preparation) $\mathrm{B} 30$ P3 F200 W2

The test results indicate the effect of both the temperature and the time of testing on the grain-size composition.

The conformity assessment is carried out in relation to the specified characteristics of the concrete mix and concrete. Tests are performed according to standard methods.

The results of the experimental research testify to the fact that the planned grain composition not always conforms to the actual production composition, as well as to the influence of a number of factors on it that significantly affect the quality of the mixture.

In case of non-conformity of the cement-concrete mixture, the adjusting of the composition and technology of manufacturing the cement-concrete mixture was performed, which included the following actions:

- Conducting repeated tests of the mixture composition.

- Registration of non-conformity of the mixture composition.

- Adjustment of a mixture of concrete with a given composition.

- Adjustment of a mixture of concrete with a given quality. 
- Control and adjustment of technological parameters of production of a cement-concrete mixture.

- Conducting repeated tests of the mixture composition.

\section{Conclusions}

On the basis of the research conducted, a method [30] was developed, intended to analyze the grain-size composition of cement-concrete road mixtures under the operational control of their quality.

The increase in the durability of road cement-concrete can be achieved by increasing the strength and density of concrete by improving the methods of selecting the composition and the use of modern chemical and mineral additives, which reduce the water consumption of a concrete mixture.

\section{References}

1. DSTU B V.2.7 - 215:2009 Construction Materials. Concrete. Composition Selection Rules.

2. DSTU - N B V.2.7 - 299:2013 The Guide to Analysis of the Composition of Heavy Concrete.

3. L. Y. Dvorkin, A. V. Mishutin, Hydrotechnical and road concrete, 215 (Zovnishreklamservis, Odesa, Ukraine, 2012)

4. DIN 1045 - 1: Tragwerke aus Beton, Stahlbeton und Spannbeton - Bemessung und Konstruktion. (2001)

5. DIN 1045 - 2: Tragwerke aus Beton, Stahlbeton und Spannbeton - Deutsche Anwendungsregeln zu DIN EN 206 -1 Beton. (2001)

6. DIN EN 206 -1: Beton - Festlegung, Eigenschaften, Herstellung und Konformität. (2000)

7. DBN V.2.3 - 4:2015 Motor-roads. Part 1. Designing. Part 2. Construction.

8. GBN V.2.3 - 37641918 - 557:2016 Motor-roads. Rigid Pavement. Design.

9. DSTU B V.2.7 - 43 - 96 Construction Materials. Heavy Concrete. Specifications.

10. DSTU B V.2.7-176:2008 (EN 206 - 1:2000, NEQ) Construction Materials. Concrete Mixtures and Concrete. General Specifications.

11. V. I. Gots, V. V. Pavliuk, , P. S. Shyliuk, Concrete and Mortars, a textbook, 2nd ed. enlarged and corrected, 567 (The Kyiv National University of Construction and Architecture, Osnova, Kyiv, Ukraine, 2016)

12. L. I. Dvorkin, Optimal Design of Concrete Compositions, 160 (Lviv University Publishing House, Lviv, Ukraine, 2016)

13. DSTU B V.2.7 - 75-98 Dense Natural Crushed Stone and Gravel for Construction Materials, Products, Structures, and Works. Specifications.

14. DSTU B V.2.7-34-2001 Crushed Stone for Construction Works from Rocky Formations and Waste of Dry Magnetic Dressing of Ferruginous Quartzites of Mining and Refining Plants and Mines in Ukraine. Specifications.

15. DSTU B V.2.7 - 210:2010 Sand from the Sifting of Fragmentation of Igneous Rocks for Construction Works. Specifications.

16. DSTU B V.2.7 - 32 - 95 Dense Natural Sand for Construction Materials, Products, Structures, and Works. Specifications. 
17. A. H. Shurhaia, N. P. Chyzhenko, High - Strength Concrete in Road Construction (Theoretical Aspects), pp. 43 - 49, 96, (NTU, Kyiv, Ukraine, 2016)

18. A. M. Onyshchenko, M. V. Garkusha, N. P. Chyzhenko, Certificate no. 81519 of Registration of the Copyright to the Assessment of Conformity of Grain - Size Composition of Cement-Concrete Road Mixtures paper from September 14, (2018)

19. DSTU B V.2.7 - 114 - 2002 (GOST 10181-2000) Concrete Mixtures. Methods of Testing.

20. DSTU ISO 3310 - 1:2017 (ISO 3310 - 1:2016, IDT) Sieves. Technical Requirements and Tests. Part 1. Laboratory Sieves Made of Metal Wire.

21. DSTU EN 45501:2016 (EN 45501:2015, IDT) Metrological Aspects of Non automatic Weighing Devices.

22. GOST 9147 - 80 Laboratory Porcelain Utensils and Equipment. Specifications.

23. DSTU B V.2.7 - 273:2011 (GOST 23732-79, MOD) Water for Concrete and Mortars. Specifications.

24. Methodological Recommendations for Determining the Initial Composition of Concrete, p. 22 (NIIZhB Gosstroya USSR, Moscow, Russia, 1983)

25. DSTU B V.2.7 - 32 - 95 Construction Materials. Dense Natural Sand for Construction Materials, Products, Structures, and Works. Specifications.

26. DSTU B V.2.7 - 71 - 98 (GOST 8269.0 - 97) Construction Materials. Crushed Stone and Gravel from Dense Rocks and Industrial Waste for Construction Work. Methods of Physical and Mechanical Tests.

27. DSTU B V.2.7 - 232:2010 Construction Materials. Sand for Construction Work. Methods of Testing.

28. DSTU B V.2.7 - 75 - 98 Construction Materials. Dense Natural Crushed Stone and Gravel for Construction Materials, Products, Structures, and Works. Specifications.

29. A. M. Onyshchenko, M. V. Garkusha, N. P. Chyzhenko, Checking the conformity of the grain-size composition of road cement concrete mixtures. Visnyk National Transport University. Series «Technical sciences». Scientific and Technical Collection p. 67-78 (Kyiv: National Transport University, 2019)

30. M 42.1 - 37641918 - 772:2018 THE METHOD of Grain - Size Analysis of Cement Concrete

Mixtures. 